\title{
Association between erythrocyte 2,3-diphosphoglycerate levels and reproductive capacity in Long-Evans rats
}

\author{
Nancy A. Noble and G. J. Brewer* \\ Department of Medicine, Harbor-UCLA Medical Center, UCLA School of Medicine, Torrance, \\ California 90509, and * Department of Human Genetics, University of Michigan Medical \\ School, Ann Arbor, Michigan 48109, U.S.A.
}

\begin{abstract}
Summary. During genetic selection of rats for high and low levels of red cell 2,3-diphosphoglycerate (DPG) the decreased fertility in Low-DPG animals was due to significantly $(P<0.01)$ fewer offspring born per litter. The rat lines were intercrossed and animals at the tails of the $F_{2}$ 2,3-diphosphoglycerate distribution were mated. Subsequent matings of $F_{3}$ offspring were monitored. Low-DPG $F_{3}$ pregnant females killed at 20 days of gestation showed significantly $(P<0.05)$ fewer corpora lutea than High-DPG $\mathrm{F}_{3}$ females. There were also significantly $(P<0.01)$ fewer corpora lutea in Low-DPG line rats compared to High-DPG rats. It is concluded that the relationship between 2,3-diphosphoglycerate levels and fertility is not due to inbreeding but to a possible genetic linkage, a shared biochemical determinant or a relationship through the effect of 2,3-diphosphoglycerate levels on oxygen delivery to tissues.
\end{abstract}

\section{Introduction}

The red cell glycolytic intermediate 2,3-diphosphoglycerate binds haemoglobin, lowering the affinity of haemoglobin for oxygen (Benesch \& Benesch, 1967; Chanutin \& Curnish, 1967). The physiological significance of variation in this oxygen transport factor has been investigated using lines of animals with genetically determined differences in red cell 2,3-diphosphoglycerate levels.

Beginning with an outbred population of hooded (Long-Evans) rats (Simonsen, Inc., Gilroy, California) showing considerable variation in red cell 2,3-diphosphoglycerate (DPG) levels, we produced a High-DPG and a Low-DPG rat line by genetic selection, the mean 2,3diphosphoglycerate values for about 100 animals being 34.8 and $22.4 \mu \mathrm{mol} / \mathrm{g}$ haemoglobin respectively (Noble \& Brewer, 1977). Intercross of the two lines and production of the $F_{2}$ animals revealed that the 2,3-diphosphoglycerate differences between the lines were due to one locus with two alleles, the High-DPG allele $(D)$ showing partial dominance over the Low-DPG allele (d) (Noble \& Brewer, 1977). Differences at this Dpg locus produce significant differences in the oxygen transport system. The oxygen dissociation curve of Low-DPG animais is shifted 6-7 mmHg to the left of the High-DPG oxygen dissociation curve (Brewer, 1972) and the mixed venous $\mathrm{Po}_{2}$ is lower in Low-DPG animals (unpublished observation). These findings suggest that a degree of hypoxia may exist in Low-DPG animals compared to High-DPG animals. Investigations into the possible biological effects of the differences in 2,3-diphosphoglycerate concentrations have shown that animals with low levels have higher plasma cholesterol values (Noble, Oelshlegel \& Brewer, 1978) and a slower rate of learning (T'so, Baker, Noble \& Brewer, 1975) than animals with high levels. In this paper we present data on reproductive capacity in animals which differ at this locus. 


\section{Materials and Methods}

\section{Experiment 1}

During the genetic selection, animals were mated solely on the basis of their red cell 2,3-diphosphoglycerate levels. Animals with the most extreme values were mated to the most distantly related animals with similar levels. Pairs were placed together for 20 days and then separated. Females were placed alone in delivery cages and were checked daily for offspring. When a litter was found, its size and the date of birth were recorded. Sterile matings, i.e. those producing no viable offspring, were noted. Between 42 and 45 days of age, young were weighed, numbered, sexed and bled for red cell 2,3-diphosphoglycerate, adenosine triphosphate and haemoglobin determinations. Data from generations 5 through 11 were used for this report. After generation 3, selection for high and low 2,3-diphosphoglycerate levels was virtually complete with respect to the major Dpg locus.

\section{Experiment 2}

The rats used were $F_{3}$ animals of the intercross of High-DPG and Low-DPG line animals. The mating scheme is shown in Text-fig. 1. The rats of each strain, 5 females and 5 males, were intercrossed to produce $F_{1}$ animals. Animals from the tails of the $F_{2}$ 2,3-diphosphoglycerate distribution were mated to produce $\mathrm{F}_{3}$ animals whose genotypes at the $D p g$ locus were virtually certain to be $d d$ or $D D$. Each $F_{3}$ female was mated with an $F_{3}$ male of similar 2,3-diphosphoglycerate level. Mating was confirmed by the presence of spermatozoa in the vaginal smear. About one-third of the females were allowed to give birth and their litters were counted, weighed and sexed as soon as they were found. On Day 2 post partum, litters were reduced to 6 or fewer young to remove at least part of the effect of litter size on weight gain until weaning.

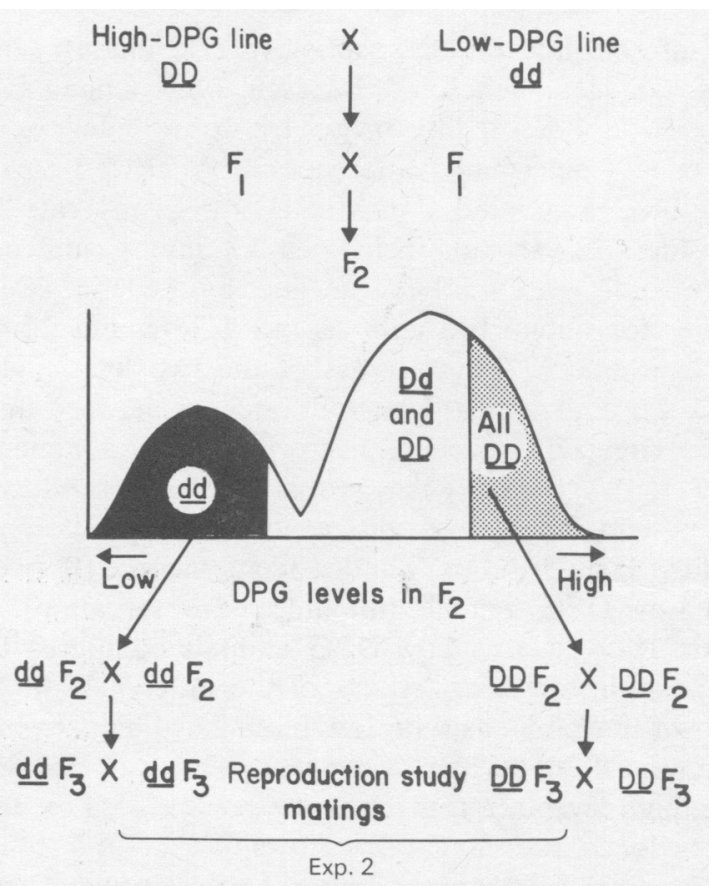

Text-fig. 1. Diagram of mating background of $\mathrm{F}_{3}$ rats used for Exp. 2: $d$ represents the Low-DPG allele and $D$ the High-DPG allele. 
The rest of the mated females were killed at 20 days of gestation. The number and positions of live fetuses and resorptions in the uterine horn were noted. Corpora lutea were counted as a measure of the number of ovulations. The fetuses were delivered by hysterotomy, cleaned of placenta and membranes and weighed. They were then examined for malformations and their sex determined.

\section{Experiment 3}

Counts were made of corpora lutea in pregnant animals (6-8 months of age) from the High-DPG line and the Low-DPG line. The procedure was as in Exp. 2 except that animals were sometimes killed before 20 days of gestation. Only corpora lutea were enumerated.

Except where otherwise indicated Student's $t$ tests were used to test for statistically significant differences.

\section{Results}

\section{Experiment 1: study of reproduction in the original High-DPG and Low-DPG lines}

The details are given in Table 1. Regression of each measure on generation number showed that generation number did not explain a significant part of the variation in these variables (Dixon \& Massey, 1969). Although 17.1\% of Low-DPG and $15 \cdot 8 \%$ of High-DPG matings did not produce offspring, a test for proportions (Dixon \& Massey, 1969) shows that this difference was not significant (Table 1).

Table 1. Reproductive capacity in High-DPG and Low-DPG strain rats

\begin{tabular}{|c|c|c|c|c|}
\hline & \multicolumn{2}{|c|}{ High-DPG group } & \multicolumn{2}{|c|}{ Low-DPG group } \\
\hline & $\begin{array}{l}\text { No. of mated } \\
\text { females }\end{array}$ & Mean \pm s.d. & $\begin{array}{l}\text { No. of mated } \\
\text { females }\end{array}$ & Mean \pm s.d. \\
\hline $\begin{array}{l}\text { Sterility } \\
\text { (no. of females sterile/ } \\
\text { total no. of matings) }\end{array}$ & 69 & 0.16 & 95 & $0 \cdot 18$ \\
\hline $\begin{array}{l}\text { Fecundity } \\
\text { (no. of offspring/mated } \\
\text { female) }\end{array}$ & 69 & $8 \cdot 0 \pm 4 \cdot 2$ & 95 & $5 \cdot 9 \pm 3 \cdot 7^{*}$ \\
\hline Litter size & 58 & $9 \cdot 5 \pm 2.6$ & 78 & $7 \cdot 2 \pm 2.7^{*}$ \\
\hline $\begin{array}{l}\text { Litter size in lactating } \\
\text { females only }\end{array}$ & 58 & $9 \cdot 5 \pm 2.6$ & 61 & $7 \cdot 1 \pm 2 \cdot 6^{*}$ \\
\hline $\begin{array}{l}\text { Viability in lactating } \\
\text { females (no. of offspring } \\
\text { surviving/no. of offspring } \\
\text { born) }\end{array}$ & 57 & $0.87 \pm 0.16$ & 61 & $0.85 \pm 0.22$ \\
\hline
\end{tabular}

* Significant difference between groups: $P<0.01$ (Student's $t$ test).

Mean fecundity, or offspring born per mating, was significantly different $(P<0.01)$ such that High-DPG animals produced about $2 \cdot 1$ more offspring per mating (Table 1). Mean litter size at birth, a measure which excludes sterile matings, was also significantly $(P<0.01)$ greater in the High-DPG line (Table 1). In the Low-DPG line, a number of females delivered young and did not nurse them (non-lactating females). In such litters, young could have been lost before litter size was recorded. However, Table 1 shows that if non-lactating females are excluded from consideration, the Low-DPG litter size changed very little and remained significantly $(P<$ $0.01)$ smaller than High-DPG litter size. Only litters of lactating females were used to examine 
viability, or proportion of offspring surviving compared to offspring born, and there was no difference between the lines (Table 1).

The sex ratio in young surviving to 6 weeks from litters of generations 5 through 11 was examined using a test for proportions of males. There were 157 male of 331 total Low-DPG offspring and 216 male of 420 total High-DPG offspring, i.e. a sex ratio of males to females of 0.9 and 1.06 for Low-DPG and High-DPG strains respectively. This difference was not statistically significant when a test for proportions was used (Dixon \& Massey, 1969).

\section{Experiment 2: study of reproduction in the $F_{3}$ intercross}

In the groups that were allowed to go to term, the mean litter sizes for High-DPG females and Low-DPG females were not significantly different at the $10 \%$ level of probability using a Student's $t$ test (Table 2). There were no non-lactating females in this group.

Table 2. Numbers of young in $F_{3}$ females (a) allowed to litter or (b) killed at Day 20 of gestation

\begin{tabular}{|c|c|c|c|c|c|}
\hline & & \multicolumn{2}{|c|}{ High-DPG group } & \multicolumn{2}{|c|}{ Low-DPG group } \\
\hline & & No. of litters & Mean \pm s.d. & No. of litters & Mean \pm s.d. \\
\hline \multirow[t]{3}{*}{ (a) } & $\begin{array}{l}\text { Litter size at birth } \\
\text { Mean weight of young (g) }\end{array}$ & 12 & $9 \cdot 3 \pm 2 \cdot 2$ & 11 & $8 \cdot 5 \pm 2 \cdot 3$ \\
\hline & At Day 1 & 7 & $6.4 \pm 0.3$ & 10 & $6 \cdot 2 \pm 0.4$ \\
\hline & At Day 22 & 7 & $43.6 \pm 8.0$ & 10 & $43 \cdot 6 \pm 4 \cdot 5$ \\
\hline \multirow[t]{6}{*}{ (b) } & $\begin{array}{l}\text { Litter size } \\
\quad \text { (live fetuses) }\end{array}$ & 20 & $10 \cdot 4 \pm 1 \cdot 5$ & 20 & $8 \cdot 8 \pm 1 \cdot 7^{* *}$ \\
\hline & $\begin{array}{l}\text { Ovulations } \\
\quad \text { (corpora lutea) }\end{array}$ & 20 & $12 \cdot 4 \pm 2 \cdot 1$ & 20 & $11 \cdot 0 \pm 1 \cdot 9^{*}$ \\
\hline & $\begin{array}{l}\text { Prenatal loss } \\
\text { (no. of resorptions) }\end{array}$ & 20 & $0.8 \pm 1 \cdot 3$ & 20 & $1 \cdot 2 \pm 1 \cdot 2$ \\
\hline & $\begin{array}{l}\text { Implantations } \\
\text { (resorptions + live fetuses) }\end{array}$ & 20 & $11 \cdot 2 \pm 1 \cdot 5$ & 20 & $10 \cdot 0 \pm 1 \cdot 4^{*}$ \\
\hline & $\begin{array}{l}\text { Ovum loss } \\
\quad \text { (ovulations - implantations) }\end{array}$ & 20 & $1 \cdot 3 \pm 1 \cdot 2$ & 20 & $1 \cdot 0 \pm 1 \cdot 2$ \\
\hline & Fetal weight (g) & 17 & $4 \cdot 0 \pm 0 \cdot 2$ & 17 & $4 \cdot 3 \pm 0 \cdot 6$ \\
\hline
\end{tabular}

Significant differences between group means: ${ }^{*} P<0.05,{ }^{* *} P<0.01$ (Student's $t$ test).

Although mean offspring weight at Day 1 was greater for High-DPG young, it was not significantly so (Table 2). After the litter sizes were reduced at Day 2 to a mean size of 5.6 for both groups, the mean weight at weaning ( 22 days of age) was the same for both strains (Table 2).

The results for the killed, pregnant females (Table 2) show that the mean litter size was significantly greater for genotypically High-DPG mothers $(P<0.01)$ and that the majority of the difference in live fetuses at 20 days of gestation appeared to be due to ovulation differences. Another part of the litter size difference appeared to be due to increased fetal loss (resorptions) in Low-DPG animals, although this difference did not attain statistical significance. Implantation differences reflected the ovulation differences. The ovum loss was greater, though not significantly so, in High-DPG mothers. No obvious malformations were noted in any of the offspring. Mean fetal weights did not differ. The sex ratios at Day 20 of gestation were 1.13 (77 males, 68 females) and 1.18 (94 males, 80 females) for the Low-DPG and High-DPG groups, respectively. 


\section{Experiment 3: study of corpora lutea in High-DPG and Low-DPG lines}

A total of 11 pregnant females from each line were killed between 16 and 20 days of gestation. The mean \pm s.d. numbers of corpora lutea were $14.4 \pm 2.0$ in High-DPG females and $10.7 \pm 2.2$ in Low-DPG females $(P<0.001)$.

\section{Discussion}

Decreased fertility in Low-DPG animals would result if alleles lowering reproductive capacity became fixed in the Low-DPG line at a locus unlinked to the Dpg locus. If this were the case, animals in the $F_{3}$ generation with low red cell 2,3-diphosphoglycerate levels should show the same distribution of reproductive capacities as $F_{3}$ generation animals with high 2,3diphosphoglycerate levels. The finding that the association remained in $F_{3}$ animals strongly suggests either a true physiological basis for the association or linkage between genes determining reproductive capacity and 2,3-diphosphoglycerate levels. Results from our study of $\mathrm{F}_{3}$ animals show that the litter size difference seen in High-DPG and Low-DPG rat lines is maintained in the pregnancies of $F_{3}$ females. Non-lactating females, on the other hand, which were fairly common in Exp. 1, were not seen in $F_{3}$ females. Further, by the time of Exp. 3 non-lactating females had been completely eliminated from the Low-DPG line. This indicates that failure to lactate was due to inbreeding. The litter size component of the fertility difference, however, remains clearly present in the two lines.

The study of the fate of ovulated eggs in utero in the $F_{3}$ segregants shows that differences in the number of ovulations are primarily responsible for litter size differences. The genotypically $D D$ females gave birth to more young than did the $d d \mathrm{~F}_{3}$ females although the difference did not attain statistical significance (Table 2). However, in the group killed at 20 days of gestation there were significantly $(P<0.01)$ more live fetuses in $D D \mathrm{~F}_{3}$ females than in $d d \mathrm{~F}_{3}$ females. If the live fetuses and the young born in the two $F_{3}$ studies are combined, the litter size difference remains highly significant $(P<0.01)$, suggesting that the smaller number of females allowed to go to term was responsible for the lack of significant difference in these animals.

If it is assumed that the association is not due to genetic linkage of the Dpg locus with a fertility-determining locus, two additional explanations for the associations can be considered. The first is our working hypothesis that differences in 2,3-diphosphoglycerate levels cause ovulation differences by bringing about oxygen transport differences. A reasonable possibility is that low 2,3-diphosphoglycerate levels lead to partial pressures of oxygen in ovarian tissues which are low enough to affect ovarian function. The 2,3-diphosphoglycerate differences are reflected in 6-7 $\mathrm{mmHg}$ differences in the whole blood $P_{50}$ (partial pressure of oxygen required for half maximal saturation of haemoglobin with oxygen). This means that unless cardiac output is increased in Low-DPG animals, the ovarian tissue may be forced to function at lower tissue oxygen concentrations to obtain adequate oxygen. While oxidative phosphorylation clearly can operate maximally at very low tissue $\mathrm{PO}_{2}$ (Kessler \& Lubbers, 1965), the function of the numerous other oxygen requiring reactions may be impaired (Clark, 1973). This is supported by the demonstration that high altitude hypoxia results in decreased fertility in rats (Altland, 1949a, b). The 2,3-diphosphoglycerate-fertility relationship could also arise from independent effects of an additional factor on both 2,3-diphosphoglycerate levels and ovulation. This factor could be the activity of the glycolytic control enzyme phosphofructokinase. Levels of red cell glycolytic intermediates in High-DPG and Low-DPG strain rats (Noble \& Brewer, 1972) and in $\mathrm{F}_{1}$ and $\mathrm{F}_{2}$ animals (unpublished data) strongly suggest that alleles at the Dpg locus act by producing different red cell phosphofructokinase activities in vivo. The studies of Chassin, Kruckeberg \& Brewer (1978) and Noble \& Tanaka (1981) indicate that the Dpg locus may be a phosphofructokinase structural locus. That this phosphofructokinase difference also affects ovarian function is currently under investigation. 
These results indicate that some factor selected in relation to selection for red cell 2,3-diphosphoglycerate level has an effect on fertility, and, more specifically, on the number of ovulations in female rats. Further work will determine if the key factor is related to oxygenation, phosphofrucktokinase activity in reproductive tissues or some third factor determined by a linked gene. The factor which influences number of ovulations in rats may also have an effect in women and could be related to the familial occurrence of fraternal twinning in man.

We thank V. Crews and T. Leonard for valuable technical assistance. This work was supported by Training Grant 50T01-GM-0071 and Biomedical Research Grant 1 ROL HL 22672 from the National Institutes of Health.

\section{References}

Altland, P.D. (1949a) Breeding performance of rats exposed repeatedly to 18,000 feet simulated altitude. Physiol. Zool. 22, 235-246.

Altland, P.D. (1949b) Effect of discontinuous exposure to 25,000 feet simulated altitude on growth and reproduction of the albino rat. J. exp. Zool. 100, 1-17.

Benesch, R. \& Benesch, R.E. (1967) The effect of organic phosphates from the human erythrocyte on the allosteric properties of hemoglobin. Biochem. Biophys. Res. Commun. 26, 162-167.

Brewer, G.J. (1972) Clinical implications of variation in erythrocyte oxygen affinity. A. Blood storage. B. Arteriosclerosis. In Oxygen Affinity and Red Cell Acid Base Status, pp. 629-645. Eds P. Astrup \& M. Rorth. Academic Press, New York.

Chanutin, A. \& Curnish, R.R. (1967) Effect of organic and inorganic phosphates on the oxygen equilibrium of human erythrocytes. Arch. Biochem. Biophys. 121, 96-102.

Chassin, S.L., Kruckeberg, W.C. \& Brewer, G.J. (1978) Thermal inactivation differences of phosphofructokinase in erythrocytes from genetically selected High and Low DPG strains. Biochem. Biophys. Res. Commun. 83, 1306-1312.

Clark, L.C., Jr (1973) A polarographic enzyme electrode for the measurement of oxidase substrates. In Oxygen Supply, pp. 120-128. Eds E. Kessler, D. F. Bruley, L. E. Clark, Sr, D. W. Lubbers, I.A. Silver \& J. Strauss. University Park Press, Baltimore.
Dixon, W.J. \& Massey, FJ., Jr (1969) Introduction to Statistical Analysis, 3rd edn. McGraw-Hill, New York.

Kessler, M. \& Lubbers, D.W. (1965) Bestimmung des kritischen sauer stoffdruches an isolierten leber mitochondrien. Pflugers Arch. Ges. Physiol. 281, 50.

Noble, N.A. \& Brewer, G.J. (1972) Studies of the metabolic basis of the ATP-DPG differences in genetically selected High and Low ATP-DPG rat strains. In Hemoglobin and Red Cell Structure and Function, pp. 155-164. Ed. G. J. Brewer. Plenum Press, New York.

Noble, N.A. \& Brewer, G.J. (1977) Identification of a major locus contributing to erythrocyte 2,3diphosphoglycerate variability in hooded (LongEvans) rats. Genetics, Princeton 85, 669-679.

Noble, N.A. \& Tanaka, K.R. (1981) Erythrocyte phosphofructokinase in rat strains with genetically determined differences in 2,3-diphosphoglycerate levels. Biochem. Genet. 19, 61-73.

Noble, N.A., Oelshlegel, F.J., Jr \& Brewer, G.J. (1978) Association between cholesterol and 2,3-diphosphoglycerate in genetically selected hooded rat lines. Biochem. Genet. 16, 39-44.

Ts'o, T.O.T., Baker, S.A., Noble, N.A. \& Brewer, G.J. (1975) Differences in the lever-pressing behavior in two strains of rats. Physiol. Behav. 14, 719-723.

Received 21 May 1981 